\title{
MANAGEMENT OF RECTAL PROLAPSE IN CHILDREN AS A DAY CARE PROCEDURE
}

\author{
RAHMAN SM ${ }^{1}$, HASANUZZAMAN ASM ${ }^{2}$, HUDA SMS ${ }^{3}$
}

\begin{abstract}
:
Rectal prolapse is a relatively common self limiting problem in young children. The peak age of prolapse is 2-3 years, a time during which the rectal mucosa is relatively loosely adherent to the underlying muscles, pelvic floor musculature is not fully developed and sacrum is relatively flat which directs increases in intra abdominal pressure towards anus instead of the protected hollow of the pelvi's ${ }^{1,2}$. Rectal prolapse is a very common childhood problem in our country due to frequency of diarrhoeal and parasitic diseases accentuated by lack of personal hygiene and mal-nutrition, Majority of the patients are poor; majority of childhood prolapse are mucosal limited to $2-3 \mathrm{~cm}$ from anal verge ${ }^{3}$. Diagnosis of rectal prolapse is straight forward by inspection and palpation. Colonoscopy and Barium enema are indicated only to exclude any other secondary causes in suspected cases. We have managed 30 (thirty) cases of recurrent rectal prolapse after failure of medical treatment in a prospective study by injection sclerotherapy as a Day care procedure; $5 \%$ phenol in olive oil was used as sclerosing agent and the procedure was performed under general anaesthesia and caudal block. The patients were kept under observation for 4-6 hours. 28 (twenty eight) patients responded satisfactorily (93.3\%); 2 patients (6.67\%) needed open operation -rectopexy. Only one patient was admitted for 48 hours due to reactionary haemorrhage which was managed conservatively. Few patients had minor complications like constipation, diarrhoea and acute retention; all managed conservatively. There was no mortality. Injection sclerotherapy appeared to be a safe, effective and cheap procedure for management of rectal prolapse in children.
\end{abstract}

J Dhaka Med Coll. 2008; 17(2) : 116-120.

\section{Introduction:}

The typical rectal prolapse is a pouting and swollen rosette of mucosa slightly longer posteriorly than anteriorly. Mucosal prolapse usually has radial folds at the anal junction, whereas full thickness prolapse has circular folds in the prolapsed mucosa. Boys and girls are affected equally. Prolapse may be associated with bleeding but not suggestive of bleeding pattern of a polyp. Diagnosis can most often be made when a rosette of mucosa is noted at the child's anus after defecation. The prolapse either reduces spontaneously or must be manually reduced. Prolapse occurs most often during crying or straining or after a diarrhoeal disease or constipation. Any condition leading to tenesmus such as parasitic infestation, dysentery, proctitis, polyps or inflammatory bowel disease may produce rectal prolapse. Often secondary causes in children are neuromuscular problems such as meningo- myelocele or extrophy of the bladder. A rectal examination should be performed after prolapse is reduced and if there is history of rectal bleeding, should be followed by proctoscopy. Colonoscopy or contrast enema may infrequently be needed to look for polyps or other lead points, no other diagnostic studies are usually required. An acute prolapse may be reduced before oedema and swelling occurs followed by strapping of the buttocks to prevent immediate prolapse. Treatment of the precipitating cause and limitation of straining usually limit recurrence. If prolapse persists or recurs after adequate trial of appropriate medical therapy surgical intervention may be required. Many surgical techniques have been suggested and their variety and number suggest that no single approach is significantly better than other. Injection sclerotherapy can be done as an outpatient basis when prolapse is mucosal or intermittent. Sclerosing agent

1. Associate Professor, Paediatric Surgery, Dhaka Medical College \& Hospital, Dhaka.

2. Medical Officer, OPD, (Surgery), Dhaka Medical College Hospital, Dhaka.

3. Assistant Registrar, Paediatric Surgery, Dhaka Medical College Hospital \& Hospital, Dhaka.

Correspondence: Dr. Syed Mahmudur Rahman 
in the form of $5 \%$ phenol in glycerine, hypertonic $30 \%$ saline or $50 \%$ glucose is injected in four quadrants in the rectal submucosa ${ }^{4}$. Upto $90 \%$ are successful and complications are few. In rare instance, full thickness prolapse is resistant to non-surgical treatment and operation is required; the options are posterior presacral rectopexy ${ }^{5}$, Ripstein approach ${ }^{6}$, Lockhart Mummary procedure ${ }^{7}$. Ekehon's rectopexy ${ }^{8}$, thierschs suture ${ }^{9}$, Transomal sleeve resection ${ }^{10}$, linear cauterization ${ }^{11}$ etc.

\section{Materials and Methods}

This is a prospective study and was carried out in paediatric surgery department of Dhaka Medical college Hospital between November 2005 to December 2007; total no of patients included in this study was 30 (thirty) (n-30).

\section{Inclusion criteria:}

Recurrent muscosal prolapse failed after adequate medical treatment. Rectal prolapse due to secondary cause such as polyp, growth, prolased intussusception were excluded.

\section{Diagnosis:}

All cases presented with typical history of recurrent prolapse followed by automatic reduction or manual reposition. Inspection of the prolapsed mucosa during squatting or straining was diagnostic of rectal prolapse. Per Rectal digital examination and proctoscopy were done routinely.

Routine Blood count $(\mathrm{CBC})$, routine examination of stool and urine, were done for pre anaesthetic check up. Colonoscopy and contrast examination or large gut were not done routinely.

Pre-operative large gut preparation included absolute liquid diet, oral amoxycillin / ciprofloxacin and metronidozole 2 days before procedure; single oral laxative was given on the previous evening. $5 \%$ phenol in olive oil was the sclerosing agent used it was freshly prepared from a renowned local pharmacy and was autoclaved one day before the procedure.

Under general anesthesia, at lithotomy position the sclerosing agent was injected at 3,6,9 and 12 o'clock position by $10 \mathrm{cc}$ syringe with wide bore needle strictly in the submucusal plain. Accidental puncture of blood vessel was ensured by withdrawing the piston and checking for blood after completion of the procedure the rectum was packed with a hot wet mop for 5-8 minutes. The mop was than withdrawn gently and the injection site was checked for any bleeding; then rolled gauze pack soaked in providone iodine solution and lubricated by Xylocain jelly was kept in situ and the patent was sent to observation room by the side or the O.T after recovery from anesthesia.

After 3-4 hours the gauze pack was removed and the patients sent home with proper advice. If needed patients were admitted in the ward. All patients were followed up 3 days, 7 days, 1 month and 6 months after procedure. The cases which failed after sclerotherapy and medical treatment were admitted for open surgery.

\section{Results:}

A total number of 30 cases (n-30) were included in this study. Out of them 18 patients $(60 \%)$ were male and 12 patients (40\%) were female (Table -I). Age ranged from 112 to 11 years; maximum number of patients were within 2-5 years $(53.33 \%)$ (Table -II). Number of patients declined with increasing age possibly due to development of pelvic floor musculature and accentuation of sacral hollow. Complications following injection sclerotherapy has been shown in Table-III.

\section{Table -I}

Distribution of Sex (n-30)

\begin{tabular}{lcc}
\hline Sex & No. of patients & Percentage \\
\hline Male & 18 & $60 \%$ \\
Female & 12 & $40 \%$ \\
\hline
\end{tabular}

Male to female ratio $3: 2$

Table -II

Age distribution (n-30)

\begin{tabular}{lcc}
\hline Age in years & No. of patients & Percentage \\
\hline $1.5-2$ & 04 & 13.33 \\
$2-5$ & 16 & 53.33 \\
$5-8$ & 06 & 20 \\
$8-10$ & 2 & 6.67 \\
$10-11$ & 2 & 6.67 \\
\hline
\end{tabular}

This table shows rectal prolapse mainly occurring in early childhood and gradually declining in later childhood. 


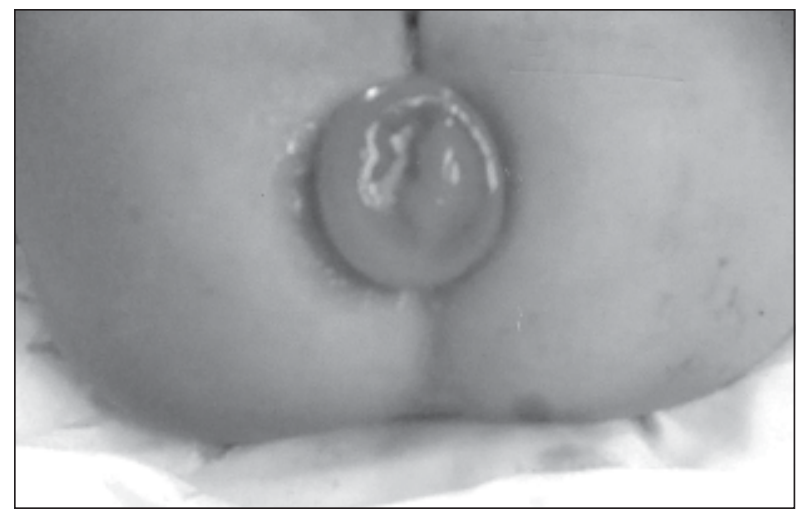

Fig.-1: Mucosal prolapse in a 3 years old male child

Table -III

Complications after sclerotherapy

\begin{tabular}{lc}
\hline Complications & $\begin{array}{c}\text { No. of } \\
\text { patients }\end{array}$ \\
\hline Primary hemorrhage & \\
(Brisk bleeding from & \\
injection site not significant \\
controlled by a hot wet & \\
mop for 5 minutes) & 12 \\
Reactionary hemorrhage & 1 \\
Secondary hemorrhage & None \\
Acute reteention of urine & 2 \\
Fever & 5 \\
Absess / Septicaemia & None \\
Diarrhoea & 2 \\
Constipation & 4 \\
Recurrence & 2 \\
\hline
\end{tabular}

\section{Discussion:}

In children rectal prolapse occurs most often during crying or straining or after a diarrhoeal illness or constipation ${ }^{1}$; in addition parasites, proctitis, polyps or inflammatory bowel disease may result in rectal prolapse due to tenesmus. Diagnosis is straight forward in most cases; a digital rectal examination should be performed after the prolapse is reduced-spontaneously or manually and if there is a history of rectal bleeding should be followed by proctoscopy. Colonoscopy and contrast enema may infrequently be needed to look for polyps or other lead points, no other diagnostic studies are usually required ${ }^{12}$.

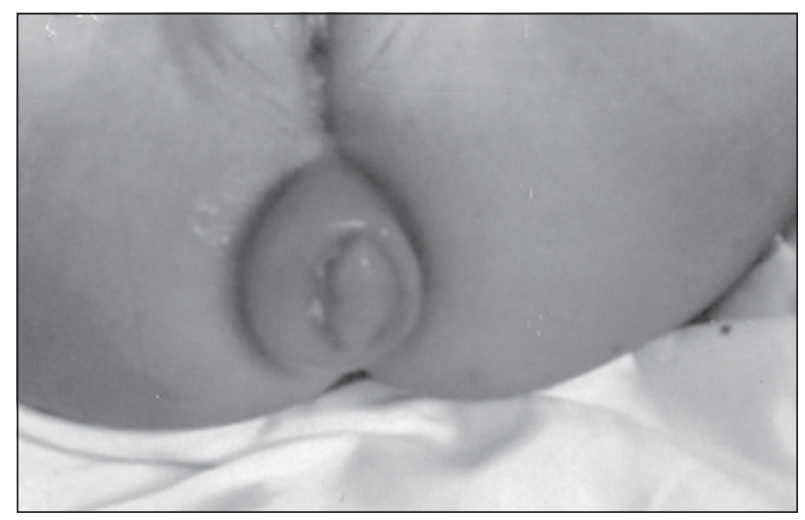

Fig.-2: Mucosal prolapse in a 212 years old female child

An acute prolapse may be reduced easily before oedema and swelling occurs and the parents must be taught to reduce the prolapse promptly after recurrence; if oedema has been formed gentle squeezing pressure may be needed. Treatment of the precipitating cause and limitation of straining usually limit recurrence. Improvement of diarrhoea or constipation, postponment or limiting toilet training and medical therapy for parasites, amoebiasis and health education to improve hygienic condition may solve the problem in 1-2 months. If prolapse persists for several months after an adequate trial or appropriate medical therapy surgical intervention may be required.

Injection sclerotherapy for recurrent mucosal rectal prolapse may be carried out as a day care procedure under general anaesthesia. Sclerosing agent in the form of $5 \%$ phenol in glycerine, hypertonic $30 \%$ saline or $50 \%$ glucose is injected in 4 quadrant strictly in the submucosal plain, the technique has been well described by wyllie ${ }^{13}$. Upto $90 \%$ of first treatment are successful and complications are few. Bleeding, infection, strictures and abscesses have all been reported occasionally.

In rate instance, full thickness prolapse is resistant to non surgical treatment and operation is required, the options are presacral rectopexy, Ripstein approach, the lockhantMammary procedure, Ekhon's rectopexy, thiersch suture, transverse sleeve resection, linear cauterization etc. 
In this study, 30 patents were studied (n-30); 18 cases were male $(60 \%)$ and 12 were female (40\%) Male; female was 3:2 showing slight male prepondarance. Earliest presentation in this study was at 1.5 years. Maximum presentation was in early childhood between 2-8 years; more than $50 \%$ patients presented between $2-5$ years. Poor development of pelvic floor musculature and sacral hollow and loose attachment of rectal muscosa to underlying muscles may be responsible for relative high incidence during this age group. Diarrhoea, dysentery are also frequent in our country during this period. Only mucosal prolapse not responding to adequate medical treatment were included in this study. In this study diagnosis was made from typical history, inspection of rosette of mucosa at the child's annus after defecation, crying or straining; per rectal digital examination and proctoscopy were done routinely to exclude polyp or any mass lesion inside rectum. Sweat test for cystic fibrosis was not done because these disease is fortunately rare in our country. and none was found during this study period.

It is assumed that the sclerosing agent produce an inflammatory response and scar with considerable submuscosal and perirectal fibrosis which prevents prolapse by causing adhesion of loosely adherent rectal mucosa to the underling muscles ${ }^{13}$.

Complication following injection sclerotherapy has been listed under table - III, primary bleeding during injection could be minimized if the correct submucosal plain can be reached. Inflammatory oedema of the prolapsed bowel was corrected by conservative treatment prior to injection which could reduce bleeding and sepsis during and after injection. Only one patient in this study was admitted for reactionary hemorrhage it was treated by packing the rectum overnight under sedation; no blood transfusion was needed. Two patients needed catheterization for acute retention which is common after any perianal procedure or surgery. Catheter was removed after 48 hours. Five patients had fever of mild to moderate degree but responded satisfactorily to antibiotics - ciprofloxacin, metronidazol, and hip bath with providone iodine solution. Four patients had constipation for 1-2 weeks; stool softners in the form of syp. lactulose and liquid paraffin for 2 weeks. All patients were advised to take plenty of vegetables and liquid to avoid constipation. There was no evidence of septicaemia and absess formation. Two patients had recurrence of prolapse after injection; one of them was received injection sclerotherapy on 2 nd occasion after 3 months and there was no recurrence; further injection was not given is the other case due to constipation. Rectal dilatation with Hegar's dilator solved the problem of constipation and later presacral rectopexy was done. There was no mortality or troublesome morbidity in this study.

\section{Conclusion:}

Management of mucosal rectal prolapse in children by injection sclerotherapy as a day care procedure is safe, cheap and effective. Avoidance of constipation, early treatment of diarrhoea and adherence to personal hygiene by patient and care givers are needed to avoid recurrence. Prior bowel preparation, reduction of inflammation of prolapsed bowel and proper sterilization of the sclerosing agent are needed to prevent infection or septicemia. However large scale study should be carried out to establish this method of treatment of rectal prolapse as safe and effective.

\section{References:}

1. Hendren WH: constipation caused by amterior location of the anus and its surgical correction, J Paediatr Surg. 1978; 13: 505.

2. Lockhart- Mummery JP : Surgical procedures in general practice: rectal prolapse. BMJ 1939; 1: 345 ,

3. Oneil, Rowe, Ctrobfeld, Pediatric surgery. Vol-2 5th edition. St. Louis: Mosby; P. 1453

4. Kay NRM, Zachary RB: The treatment of rectal prolapse in children with injection of 30\% saline solutions, J Pediatr Surg 1970; 5: 334.

5. Ashcraft KW, Gared JL, Holder TM: Rectal prolape 17 year experience with the posterior repair and suspension, J Pediarr sung 1990; 25: 992.

6. Atremeir WA et al Nineteen years experience with the one state perineal repair of rectal prolapse. Ann. Surg. 1971; 173: 993. 
7. Marbouby Det al: Anatomic basis of the lockhartMummery procedure in the treatments or total rectal prolapse in children. Bull Assoc. Anat 1993. 74: 19.

8. Schepens MA, Verheist AA: Re apprisal of Fkehon's rectopexy in the management of rectal prelape in children. J Pediatr Surgy 1993; 28: 1494.

9. Sempsky WT, Rojentein BJ : The cause of rectal prolapse in children, Ann Dis child 1989; 142 : 338.
10. Chawlas WJ. Transanal mucosal sleeve resection for the treatment of rectal prolapse in children. $\mathrm{J}$ padiarr surg 1990; 25: 715.

11. Hight DW et al; Linear cauterization for the treatment of rectal prolapse in infant and children, surg Gynecoll object 1982; 154:400.

12. Severijnen $\mathrm{R}$ et al; Rectal prolapse in children Neth surg 1989; 41: 149.

13. Wyllie GG! The injection treatment of rectal prolapse, J Padiatr Surg. 1979; 14: 62. 